\title{
Effect of Temperature and Ionic Strength on Adsorption-Desorption Behaviour of Penoxsulam on Six Soils
}

\author{
Namrata Gururani $^{1 *}$, Gajan Pal ${ }^{1}$, Anjana Srivastava ${ }^{1}$ and Prakash Chandra Srivastava ${ }^{2}$ \\ ${ }^{1}$ Department of Chemistry, College of Basic Sciences and Humanities, ${ }^{2}$ Department of Soil \\ Science, College of Agriculture, G. B. Pant University of Agriculture and Technology, \\ Pantnagar -263145,Uttarakhand, India \\ *Corresponding author
}

\section{A B S T R A C T}

\begin{tabular}{|l|}
\hline Ke y w or d s \\
Adsorption, \\
Desorption, \\
Temperature, Ionic \\
strength, \\
Penoxsulam
\end{tabular}

In the present study adsorption-desorption behaviour of penoxsulam on six different Indian soils at different temperatures $\left(15,25\right.$ and $\left.35^{\circ} \mathrm{C}\right)$ and varied ionic strengths $(0.003$ and $0.03 \mathrm{M})$ was investigated to evaluate the effect of penoxsulam adsorption and desorption in varied soils. An increase in temperature decreased the adsorption but increased desorption of the herbicide in soils whereas on increasing the ionic strength adsorption increased effectively and desorption decreased from soils. Alkaline and neutral soils (JK-1, BD-2 and HLD-2) showed significant difference in adsorption whereas in acidic soils (LOH, HLD-1 and BH-1) this difference was only minor. Adsorption-desorption data showed statistically significant difference $(\mathrm{p} \leq 0.05)$ at different temperatures. An increase in ionic strength showed significant difference in adsorption of the neutral and basic soils (JK-1, BD-2 and HLD-2) but in acidic soils (LOH, HLD-1 and BH-1) this difference in adsorption was minor, though desorption depicted statistically significant difference $(\mathrm{p} \leq 0.05)$ in all the six soils.

\section{Introduction}

Pesticides have contributed tremendously towards increasing food production worldwide but the excessive use of pesticides has become a major topic of concern as it has ultimately ledto several environmental issues (Capel et al., 1995; Torrents et al., 1997). Rice food crop contributes around $21 \%$ of the world's food supply with Asia alone producing $90 \%$ of it. This has resulted in increased utilisation of various herbicides for weed control and is therefore frequently found in surface and ground water (Subhani et al., 2000). Herbicides are a major group of pesticides widely used to amplify the production of crops 
by deteriorating the growth of weeds and minimizing farmers toil. Weeds show extremely high persistent level with $10-15 \%$ reduction in production of rice annually in Asian countries.

At present herbicides having high efficiency are gaining interests as usage of lower dose is sufficient resulting in decreased volume of herbicides utilization (Kathiresan, 2001).

Dow Agro Science in the year 2003, introduced penoxsulam [3-(2,2difluoroethoxy)-N-(5,8 dimethoxy $[1,2,4]$ triazolo $\quad[1,5-\mathrm{c}] \quad$ pyrimidin-2-yl)- $\alpha, \alpha, \alpha-$ trifluorotoluene-2-sulfonamide], in Chile as a rice herbicide.

Penoxsulam activity as a post emergence herbicide against annual and perennial boardleaved weeds in rice crop was excellent (Roberts et al., 2003). Echinochloa crusgalli, E. colona, Ammania baccifera and Cyperus $s p$. were some of the most prominent weeds which were efficiently treated by applying appropriate dose of penoxsulam. Recommended dose as a pre-emergence and post-emergence herbicide was $25 \mathrm{~g} / \mathrm{ha}$ (3 DAT) and 20.0-22.5 g/ha (10-12 DAT) respectively (Yadav et al., 2008). Penoxsulam as compared to other herbicides is comparatively mobile in aqueous medium and therefore shows lower persistence level.

The nature of the pesticides in soil is chiefly governed by adsorption-desorption phenomenon (Gao et al., 1998; de Jonge and de Jonge, 1999) and their behaviour in the environment is influenced by the state variables of the region.

The present study was therefore undertaken to investigate the adsorption-desorption behaviour of penoxsulam on different soils with temperature and ionic strength as two different variables.

\section{Materials and Methods}

\section{Experimental Methods}

Analytical grade penoxsulam (white crystalline solid, purity 99\%) was obtained from Dow Agro Science India Pvt. Ltd. Company, Mumbai, India. All the chemicals used in the study were of analytical or HPLC grade. Six surface $(0.25 \mathrm{~cm}$ depth $)$ soils, namely soil (HLD-1 and HLD-2) from Haldwani, (JK-1) from Joelikot and (LOH-5) from Lohaghat in Uttarakhand and Budaun (BD-2) and Baheri (BH-1) in Uttar Pradesh were collected from different regions of India. Soil samples were dried crushed and passed through a $2 \mathrm{~mm}$ sieves and analysed using standard methods.

\section{Effect of temperature on adsorption- desorption of penosxulam}

To see the effect of temperature on adsorption-desorption of penoxsulam in soils studies were conducted at three different temperatures (15, 25 and $\left.35^{\circ} \mathrm{C}\right) .2 \mathrm{gm}$ soil was taken in thirty-six centrifuge tubes. Then, $0.1 \mathrm{M}$ of $1 \mathrm{ml} \mathrm{CaCl}_{2}$ and $1 \mathrm{ml}$ of $40 \mathrm{ppm}$ penosxulam were added to the centrifuge tubes. The volume was made up to $20 \mathrm{ml}$ by adding double distilled water . The resultant solutions were shaken at three temperatures $(15,25$ and $35 \mathrm{C})$ for 24 hours in duplicate. The quasi-steady equilibration time of penoxsulam in soils was determined earlier and was found to be 24 hours at $120 \mathrm{rpm}$. Hence the same equilibration time was observed in the present study. The contents were further centrifuged at $6000 \mathrm{rpm}$ for 10 min. From clear supernatant, penoxsulam was extracted by modified QuEChER'S method (Monika et al., 2017). The clear supernatants were analysed by High Performance Liquid Chromatography (HPLC). For desorption study, $0.1 \mathrm{M}$ of $1 \mathrm{ml} \mathrm{CaCl}_{2}$ was added to the pellet retained after the removal of supernatant 
and the volume was made up to $20 \mathrm{ml}$ by addition of double distilled water. The suspensions were equilibrated for $24 \mathrm{~h}$ at 120 $\mathrm{rpm}$ and centrifuged at $6000 \mathrm{rpm}$ for $10 \mathrm{~min}$. The clear supernatants were obtained and analysed as mentioned for adsorption study.

\section{Effect of ionic strength on adsorption- desorption of penoxsulam}

The effect of ionic strength on adsorptiondesorption of penoxsulam was also examined by taking $2 \mathrm{gm}$ soil in twenty-four centrifuge tubes. One ml of stock solution of penoxsulam $(40 \mathrm{mg} / \mathrm{l})$ and different volumes of $0.1 \mathrm{M}$ $\mathrm{CaCl}_{2}$ were added to get the ionic strength of 0.003 and 0.03 respectively. Final volume was made up to $20 \mathrm{ml}$ by adding requisite amount of double distilled water. The resultant solutions were shaken for 24 hours at $120 \mathrm{rpm}$ in duplicate. The contents were centrifuged for $6000 \mathrm{rpm}$ for $10 \mathrm{~min}$. From clear supernatant, penoxsulam was extracted by QuEChER'S method. The clear supernatants were analysed by HPLC. Desorption experiment was done at different ionic strength as stated above for temperature.

\section{HPLC estimation of penoxsulam analysis}

The quantitative analysis of penoxsulam solutions was done by using DionexUtimate 3000 HPLC containing C18 column, (250 x $4.6 \mathrm{~mm}$ i.d., $5 \mu \mathrm{m})$ under isocratic mode with acetonitrile $(100 \%)$ as mobile phase at a flow rate of $1 \mathrm{ml} \mathrm{min}^{-1}$ and $\mathrm{UV}$ detection at 310 $\mathrm{nm}$. The retention time of penoxsulam was 4 min under the above conditions.

\section{Results and Discussion}

In general among the various physicochemical properties of soil shown in table 1, correlation with $\mathrm{pH}$ depicted that out of the six soils, three soils (LOH-5,HLD-1 and BH-1) were acidic, one soil (HLD-2) was almost neutral and two soils (BD-2 and JK-1) were basic in nature. In general the extent of adsorption both in case of temperature and ionic strength was higher in case of acidic soils as compared to neutral soil followed by the two basic soils.

\section{Effect of temperature}

Temperature variation affected the sorptiondesorption of penoxsulam to a great extent. Increase in temperature significantly decreased the adsorption on each of the six soils. The extent of adsorption of penoxsulam in six soils followed the order LOH-5>HLD1> BH-1>HLD-2>JK-1>BD-2 at all the three temperatures. The maximum adsorption was at $15^{\circ} \mathrm{C}$ followed by 25 and $35^{\circ} \mathrm{C}$ but desorption increased with increase in temperature and the difference was significant at $\mathrm{p} \leq 0.05$ (Figure $1)$. Out of the six soils adsorption on the three acidic soils (BH-1, HLD-1 and LOH-5) was higher as compared to basic soils (HLD-2, BD-2 and JK-1) as is evident from Figure 1. Among the various soil properties the adsorption of penoxsulam showed strong correlation with soil $\mathrm{pH}$ (Table 1). At nearneutral $\mathrm{pH}$, penoxsulam exists as an anionic species, presumably due to the deprotonation of sulfonylamido group. At lower $\mathrm{pH}$ the ratio of neutral species is more than the anionic species resulting in lower solubility and lower mobility in soil (Jabusch, 2005; Alister et al., 2010). Soil LOH-5, with $\mathrm{pH}$ value of 5.36, showed maximum adsorption and minimum desorption whereas soil BD-2 having a $\mathrm{pH}$ value of 8.71 showed minimum adsorption and maximum desorption of penoxsulam at all the three temperatures (Figure 1). In addition to $\mathrm{pH}$, lower organic content $(5.94 \mathrm{~g} / \mathrm{kg})$ of BD-2 soil also attributed towards lower adsorption. The increase in temperature resulted in decrease in adsorption and increase in desorption which can be attributed to the decrease in the force of attraction between the sorbate and the sorbed phase. 
Table.1 General properties of soil samples

\begin{tabular}{|c|c|c|c|c|c|c|c|}
\hline \multicolumn{8}{|c|}{ Soil Properties } \\
\hline
\end{tabular}

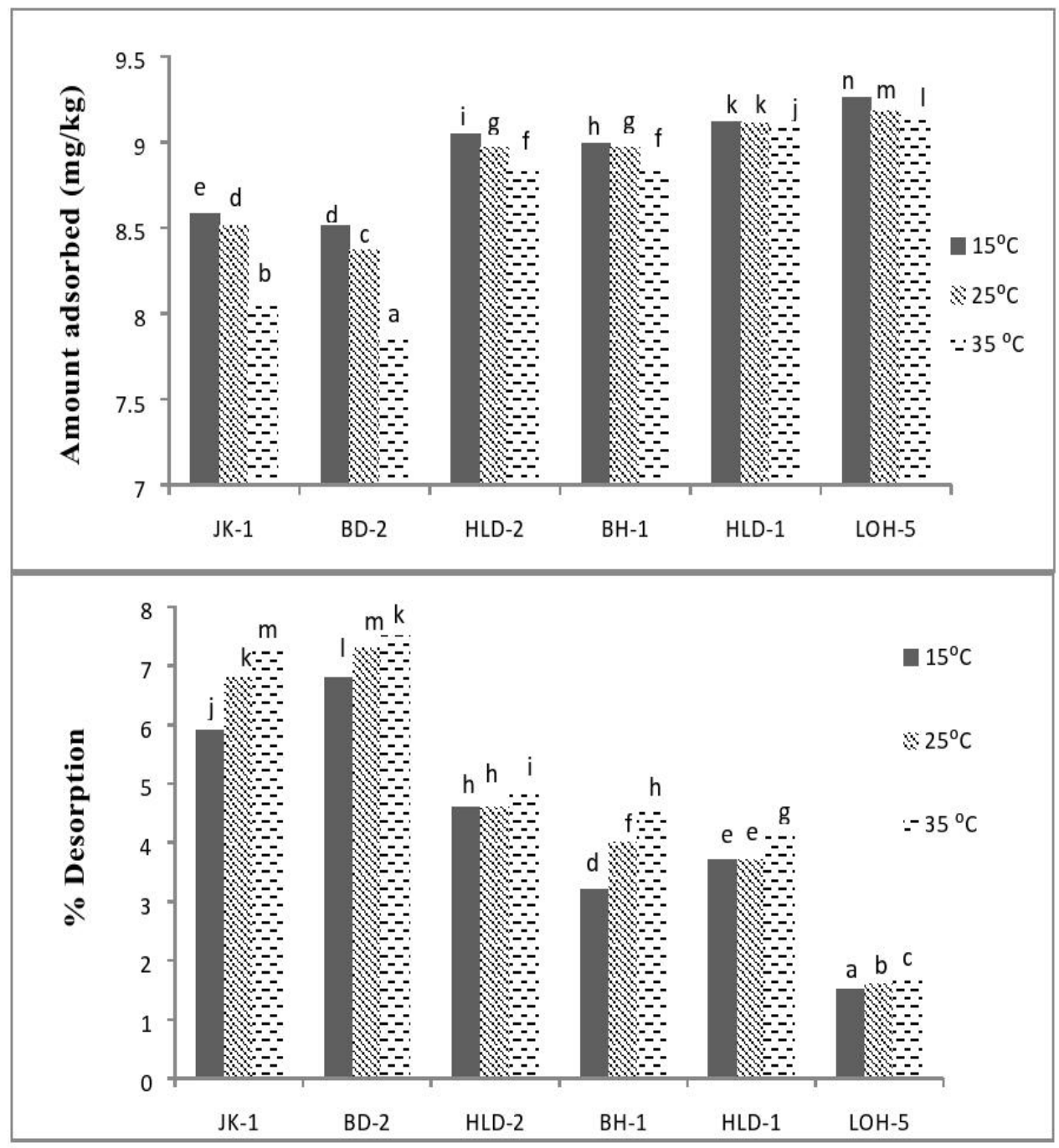

Fig.1 Penoxsulam adsorbed onto six soils and \% desorption over a range of temperatures.

Dissimilar letters over the histograms indicate statistically significant differences at $\mathrm{p} \leq 0.05$. 


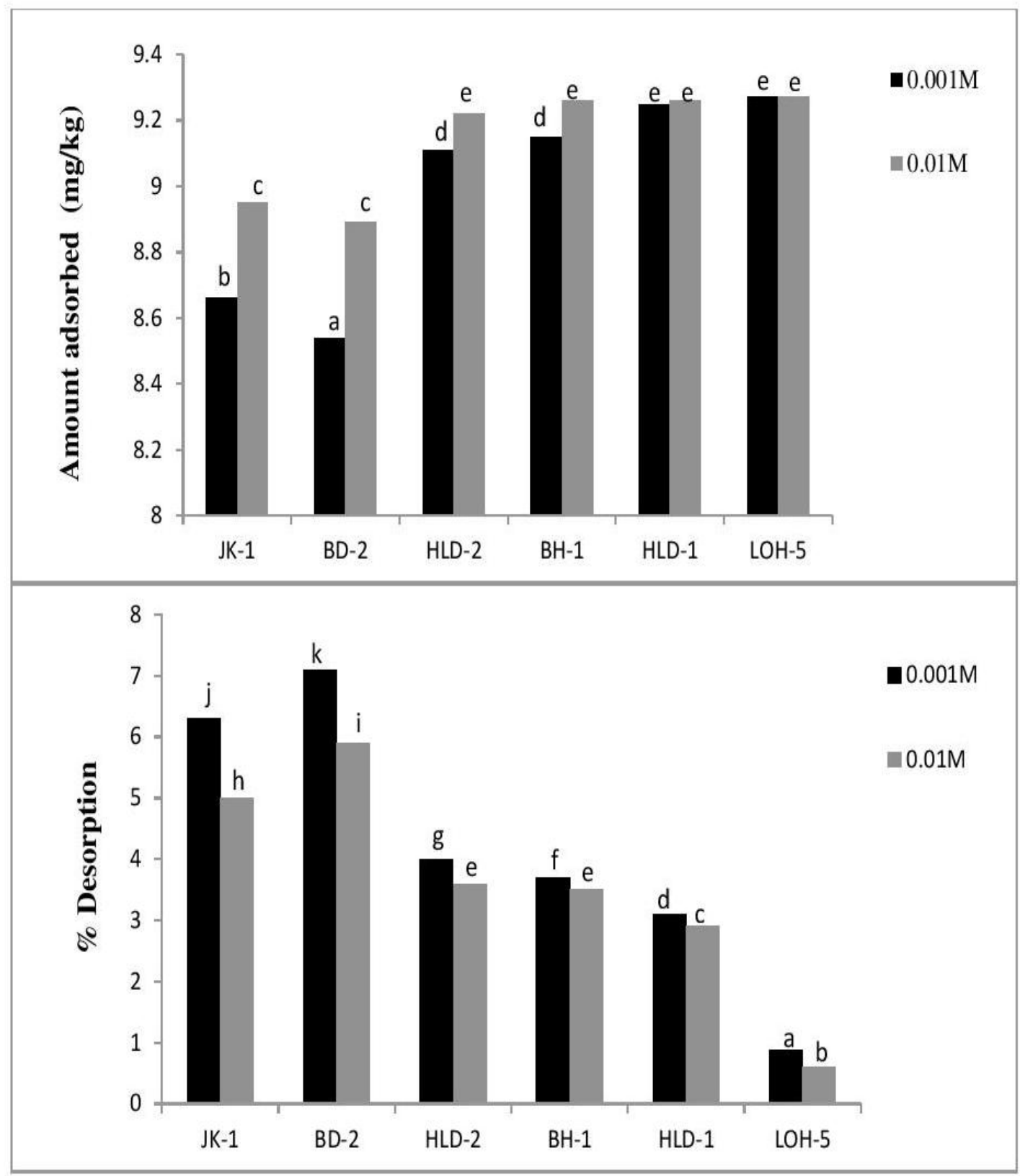

Fig.2 Penoxsulam adsorbed onto six soils and \% desorption at two different ionic strength. Dissimilar letters over the histograms indicate statistically significant differences at $\mathrm{p} \leq 0.05$.

Thus, penoxsulam can contaminate surface and ground water at high temperatures (above $35^{\circ} \mathrm{C}$ ) due to lower adsorption and higher mobility in soils.

The trend basically predicts that the process is exothermic with involvement of physical forces in nature. Yaron and Saltzman (1972) reported the adsorption of parathion on soil at three different temperatures $\left(10,30\right.$ and $\left.50^{\circ} \mathrm{C}\right)$. The adsorption was maximum at $10^{\circ} \mathrm{C}$ followed by 30 and $50^{\circ} \mathrm{C}$. Rani and Sud (2015) also reported a similar adsorptiondesorption trend of triazophos insecticide at 10,20 and $40^{\circ} \mathrm{C}$ with maximum adsorption and minimum desorption at $10^{\circ} \mathrm{C}$ followed by 
20 and $40^{\circ} \mathrm{C}$.

\section{Effect of ionic strength}

An increase in ionic strength resulted in higher adsorption of penoxsulam on soils. As evident from Figure 2, increase in adsorption was significant for the alkaline soils but in case of acidic soils (LOH-5, HLD-1 and LOH-5), adsorption was only minor when the ionic strength was increased from 0.003 to 0.03 . Similar letters in histograms of acidic soils (LOH-2, HLD-2 and BH-1) in case of adsorption show insignificant change at $\mathrm{p} \leq 0.05$. However, the overall adsorption of penoxsulam in acidic soil was more which didn't increase much as ionic strength was increased. In case of alkaline soils dissimilar letters show significant change at $\mathrm{p} \leq 0.05$. Desorption in case of all the soils decreased with increase in ionic strength with significant difference. This increase in adsorption with increase in ionic strength can be explained on the basis of the salting out phenomenon. The addition of salt affects the interaction, majorly electrostatic and $\mathrm{H}$-bonding forces at the herbicide-soil interface. In the case of penoxsulam-soil interface the addition of divalent salt $\left(\mathrm{CaCl}_{2}\right)$ increased the availability of the vacant sites on the soil surface which were otherwise being occupied by the water molecules. The salt interacts with the water molecules thereby increasing the sorption rate. Hence soils of higher ionic strength can prevent leaching of penoxsulam herbicide and not lead to ground water pollution. Kyriakopouloset al., (2006) reported similar effects of ionic strength $(0.01,1$ and $2 \mathrm{M})$ on the adsorption of herbicides (Prometryn, Alachlor and Trifluralin) onamberlite XAD-4 polymeric resin. The adsorption increased significantly as the ionic strength increased with maximum at $2 \mathrm{M}$ concentration.

The adsorption-desorption of penoxsulam by soils is affected both by temperature and ionic strength. Adsorption was comparatively more on acidic soils than in basic soils. Increase in temperature decreased the adsorption whereas desorption was increased with increase in temperature. High temperature favours desorption of penoxsulam thereby making it highly mobile leading to surface and ground water contamination. On the other hand in all the six soils adsorption increased by increase in ionic strength but desorption decreased which can prevent leaching of penoxsulam to ground water. Thus, it can be recommended that penoxsulam herbicide applied in soils with higher ionic strength, at low temperature should not contaminate ground water.

\section{References}

Capel, P.D., Ma, L., Schroyer, B.R., Larson, S.J., and Gilchrist, T.A. 1995. Analysis and detection of the new corn herbicide acetochlor in river water and rain. Environ. Sci. Technol., 29 (6): 1702-1705.

Torrents, A., Jayasundera, S., and Schmidt, W.J. 1997. Influence of the polarity of organic matter on the sorption of acetamide pesticides. J Agric Food Chem., 45(8): 3320-3325.

Subhani, A., E1-ghamry, A.M., Changyong, H., and Jianming, X. 2000. Effects of pesticides (Herbicides) on Soil Microbial Biomass-A Review. Pak J. Biol. Sci., 3 (5): 705-709.

Kathiresan, R.M. 2001. Sustainability of weed management practices in rice-black gramcropping system. In Lead paper and abstract of final biennial conference in the new millennium as eco-friendly weed management options for sustainable agriculture, University of Agriculture Sciences, Bangalore, India, 79.

Roberts, D.W., Knuteson, J.A., and Jackson, R. 2003. The dissipation of penoxsulam in flooded rice fields. In: Pesticides in Air, Plant, Soil \& Water 
Systems: XII Symposium Pesticides Chemistry, Piacenza, Italy. 349-357.

Yadav, D.B., Yadav, A., and Punia, S.S. 2008. Efficacy of penoxsulam against weeds in transplanted rice. Weed Sci., 40 (3, 4): 142-146.

Gao, J.P., Maguhn, J., Spitzauer, P., and Kettrup, A. 1998. Sorption of pesticides in the sediment of the teufelsweiher pond (Southern Germany).II: Competitive adsorption, desorption of aged residues and effect of dissolved organic carbon. Water Res., 32(7): 2089-2094.

deJonge, H., and de Jounge, L.W. 1999. Influence of $\mathrm{pH}$ and solution composition on the sorption of glyphosate and prochloraz to a sandy loam soil. Chemosphere., 39 (5): 753 763.

Monika, Srivastava, A., Suyal, A., and Srivastava, P.C. 2017. Persistence behaviour of penoxsulam herbicide in two different soils. Bull. Environ.
ContamToxicol., 99 (4): 470-474.

Jabusch, T.W., and Tjeerdema, R.S. 2005. Partitioning of penoxsulam, a new sulphonamide herbicide. J Agric Food Chem., 53 (18): 7179-7183.

Alister, C.A., Araya, M.A., and Kogan, M. 2010. Adsorption and desorption variability of four herbicides used in paddy rice production. $J$ Environ $S c i$ Heal B., 46 (1): 62-68.

Yaron, B., and Saltzman, S. 1972. Influence of water and temperature on Adsorption of Parathion by Soils 1. Soil. SciSoc Am J., 36 (4): 583-586.

Rani, S., and Sud, D. 2015. Effect of temperature on adsorption-desorption behaviour of triazophos in Indian soils. Plant Soil. Environ., 61 (1): 36-42.

Kyriakopoulos, G., Doulia, D., and Hourdakis, A. 2006. Effect of ionic strength and $\mathrm{pH}$ on the adsorption of selected herbicides on Amberlite. Int. J. Environ An Ch., 86 (3-4): 207-214.

\section{How to cite this article:}

Namrata Gururani, Gajan Pal, Anjana Srivastava and Prakash Chandra Srivastava. 2019. Effect of Temperature and Ionic Strength on Adsorption-Desorption Behaviour of Penoxsulam on Six Soils. Int.J.Curr.Microbiol.App.Sci. 8(12): 1769-1775.

doi: https://doi.org/10.20546/ijcmas.2019.812.211 